\title{
Occurrence, species distribution and antimicrobial resistance of thermophilic Campylobacter isolates from farm and laboratory animals in Morogoro, Tanzania
}

\author{
Erick V. G. Komba ${ }^{1}$, Robinson H. Mdegela ${ }^{1}$, Peter L. M. Msoffe ${ }^{182}$, Denis E. Matowo ${ }^{3}$ and Makori J. Maro ${ }^{4}$
}

1. Department of Veterinary Medicine and Public Health, Faculty of Veterinary Medicine, Sokoine University of Agriculture, P.O. Box 3021, Morogoro, Tanzania; 2. Directorate of Undergraduate Studies, University of Dodoma, P. O. Box 259, Dodoma, Tanzania; 3. Amana Regional referral Hospital, P.O. Box 25411, Dar es salaam, Tanzania; 4. Ngudu District Hospital, P.O. Box 64, Ngudu/Kwimba, Mwanza, Tanzania

Corresponding author: Erick V. G. Komba, email: babagrid@yahoo.com; ekomba@suanet.ac.tz RHM: rmdegela@yahoo.com, PLMM:makengamsoffe@yahoo.co.uk,DEM: dmatowo@yahoo.com, MJM: marojosephat@yahoo.com Received: 09-04-2014, Revised: 17-06-2014, Accepted: 24-06-2014, Published online: 03-08-2014

doi: 10.14202/vetworld.2014.559-565 How to cite this article: Komba EVG, Mdegela RH, Msoffe PLM, Matowo DE and Maro MJ (2014) Occurrence, species distribution and antimicrobial resistance of thermophilic Campylobacter isolates from farm and laboratory animals in Morogoro, Tanzania, Veterinary World 7(8): 559-565.

\begin{abstract}
Aim: To determine the carriage and antimicrobial resistance of Thermophilic Campylobacter species in the gastrointestinal tracts of farm and laboratory animals in Morogoro, Tanzania

Materials and Methods: Faecal samples were collected from farm $(\mathrm{n}=244)$ and laboratory $(\mathrm{n}=466)$ animals and were subjected to the Cape Town protocol for isolation of Campylobacter. Isolates were preliminarily identified based on potassium hydroxide string and hippurate hydrolysis tests. Polymerase chain reaction (PCR) was employed for confirmation of isolates. Antimicrobial resistance testing was done using disc diffusion method.

Results: Of the laboratory animals, $26.7 \%$ of guinea pigs $(n=30)$ and $1.2 \%$ of rats $(n=242)$ were colonized with Campylobacter. Four isolates from guinea pigs were Campylobacter jejuni and the other four were Campylobacter coli. From rats, two isolates were C. jejuni and one was C. coli. In farm animals thermophilic Campylobacter were detected from 31.6\% of sheep $(\mathrm{n}=57)$ and $60 \%$ horses $(\mathrm{n}=5)$. Of the isolates $12(57 \%)$ were $C$. jejuni (10 from sheep and 2 from horses) and the remaining were $C$. coli ( 8 from sheep and 1 from a horse). The isolates were frequently resistant to erythromycin, norfloxacin, colistin sulphate and nalidixic acid; whereas low levels of resistance were observed for ciprofloxacin and gentamicin.

Conclusion: Our study reveals carriage of antimicrobial resistant thermophilic Campylobacter in the intestines of the study animals. This highlights possibilities in involvement of these animals in the epidemiology of Campylobacter infections. Thus, there is a need to consider these animal species when planning control measures for this zoonotic bacterium.
\end{abstract}

Keywords: campylobacteriosis, cape town protocol, farm animals, laboratory animals

\section{Introduction}

Since its first recognition as a common human pathogen in 1970s the public health importance of Campylobacter has increased and is now considered to be one of the most frequent bacterial causes of human enteritis in many developing and developed countries [1-4]. The most commonly isolated agents in human infections are Campylobacter jejuni and Campylobacter coli. The former is the most frequently isolated species in the genus, causing over $80 \%$ of cases of human campylobacteriosis [5]. The species mainly colonizes in cecal and cloacal crypts in chickens [6] without invading the intestinal epithelium, unlike the colonization in mammals (such as mice, swine, rabbits, monkeys, and humans) where the organism commonly invades the host intestinal epithelial cells [7]. Other species include C. concisus, C. lari, C. upsaliensis, $C$. uleolyticus, $C$. sputorum, $C$. curvus, $C$. rectus and $C$. upsalinensis. Members of the genus Campylobacter naturally colonize a wide range of hosts, particularly

Copyright: The authors. This article is an open access article licensed under the terms of the Creative Commons Attribution License (http://creativecommons.org/licenses/by/2.0) which permits unrestricted use, distribution and reproduction in any medium, provided the work is properly cited. warm-blooded animals (both domesticated and wild) and more so in birds [8-12]. They are frequently found in contaminated food products thereby constituting a risk of zoonotic transmission to humans [13]. The primary route of transmission of these bacteria to humans is the ingestion of contaminated chicken or cross-contaminated food products associated with raw/undercooked chicken [14]. Other risk factors for the spread of campylobacteriosis include raw and inadequately pasteurized milk, contaminated water supplies, pets with diarrhoea, and occupation exposure when processing poultry in abattoirs [15].

While most animal infections with Campylobacter are asymptomatic, the typical symptoms of Campylobacteriosis in humans include profuse watery to bloody diarrhoea, abdominal pain and cramps, fever, and presence of leukocytes and red blood cells in faeces [16]. Campylobacter infections can also develop into Guillain-Barre' syndrome (GBS), an autoimmunemediated neurodegenerative disorder which causes acute neuromuscular paralysis [17]. Most cases of Campylobacter enteritis do not require antibiotic treatment because they are of short duration, clinically mild and self-limiting but antibiotic treatment is 
indicated for systemic Campylobacter infections and for severe or chronic cases of Campylobacteriosis [18]. However, a number of studies in different parts of the world have addressed the issue of antimicrobial resistance in the organisms isolated from both humans and different animal species. The development of optimal isolation protocols has increased the interest in studies on Campylobacter in different hosts. In our country, most of these studies have however been limited to humans and chickens. This undermines the contribution of other animal species in the epidemiology of the organism.

Thus, the present study was aimed at investigating on the colonization and antimicrobial resistance of thermophilic Campylobacter in faeces of farm and laboratory animals in Morogoro, Tanzania.

\section{Materials and Methods}

Ethical approval: The Institutional Review Board at Sokoine University of Agriculture, the primary author's institution, approved this study. Sample collection was done by qualified and registered veterinarians.

Study area: The study was conducted in Morogoro Municipality, eastern part of Tanzania. It involved farm and laboratory animals kept at Sokoine University of Agriculture. It is a public Institution located three $\mathrm{km}$ from Morogoro town center; offering various courses to undergraduate and postgraduate students. The University is provided with farm and laboratory animals that are used for different purposes including teaching and research.

Study animals and sample collection: The animals included in this study were apparently health farm and laboratory animals. In total, 710 animals were sampled (466 laboratory and 244 farm animals). Laboratory animals included 30 guinea pigs, 160 mice, 34 rabbits and 242 rats. Farm animals included 98 cattle, 81 goats, 57 sheep, 5 horses and 3 camels. Faecal samples were collected from study animals and immediately transported on ice to the laboratory where they were homogenised in $1.5 \mathrm{ml}$ enrichment Bolton broth (Oxoid Ltd, Basingstoke, UK) containing selective supplement and $5 \%$ of laked horse blood. While in Bolton broth the samples were incubated under a microaerophilic condition at $42^{\circ} \mathrm{C}$ for $24 \mathrm{~h}$.

Isolation of the organisms: Isolation of thermophilic Campylobacter from fecal samples adopted the Cape Town protocol with slight modification as explained by Jacob et al. [19]. Briefly a $0.45 \mu \mathrm{m}$ pore size nitrocellulose filter was overlaid on the surface of the blood agar on to which $200 \mu \mathrm{L}$ of enrichment broth containing the sample was dispensed. After 45 minutes the filter was removed and the filtrate was spread by streaking. Plates were incubated under microaerophilic conditions at $37^{\circ} \mathrm{C}$ for $72 \mathrm{~h}$ with growth of the organisms assessed after every $24 \mathrm{~h}$. Suspected Campylobacter colonies were sub cultured on blood agar for $24 \mathrm{~h}$ and then subjected to identification techniques.

\section{Identification of Campylobacter isolates}

Preliminary identification: Campylobacter isolates were preliminarily identified based on phenotypic tests namely; growth atmospheric requirements, colonial characteristics, testing for Gram negativity using the $\mathrm{KOH}$ String Test (3\% potassium hydroxide on a glass slide), motility test and the sodium hippurate hydrolysis test for differentiation of $C$. jejuni from other thermophilic Campylobacter.

Confirmation of Campylobacter isolates: Following preliminary identification Campylobacter isolates were further confirmed using a genome-based method, species specific polymerase chain reaction (PCR) Genomic DNA to be used for PCR was extracted from bacterial suspensions by boiling at $100^{\circ} \mathrm{C}$ for $10 \mathrm{~min}$. The extracted DNA was quantified by spectrophotometric measurement at a wavelength of $260 \mathrm{~nm}$. Primers F,5'CTATTTTAT TTTTGAG TGCT T G T G3' and R,5'GCTTTATT TGCCAT TTG TTT TA TTA3' (TAG COPENHAGEN A/S) were used to amplify the mapA gene (589 bp) of $C$. jejuni, whereas primers F, 5' ATTTGAAAATTGCTCCAACTATG3' and R,5'T GA TTTTATTATTTGTAGCAGCG3'(TAG COPENHAG EN A/S) were used to amplify the $c e u E$ gene (462 bp) of $C$. coli. Each reaction was performed in a $50 \mu 1$ total volume containing $10 \mu \mathrm{l}$ primer mix (12 pmol of each primer), $25 \mu$ l Green master mix (Qiagen, MA, USA), $2 \mu 1$ DNA template and $13 \mu 1$ milli Q water. Amplification reactions were run in Biometra $\mathrm{T} 3$ thermocycler (Fisher Scientific, UK), with the following program: an initial denaturation at $95^{\circ} \mathrm{C}$ for $5 \mathrm{~min}$ followed by 34 cycles of denaturation at $94^{\circ} \mathrm{C}$ for $20 \mathrm{~s}$, annealing at $50^{\circ} \mathrm{C}$ for $20 \mathrm{~s}$ and polymerization at $72^{\circ} \mathrm{C}$ for $1 \mathrm{~min}$. A final extension was performed at $72^{\circ} \mathrm{C}$ for $5 \mathrm{~min}$. Samples were then maintained at $4{ }^{\circ} \mathrm{C}$ until they are processed. The amplification generated $589 \mathrm{bp}$ and 462 bp DNA fragments corresponding to $C$. jejuni and $C$. coli respectively. The PCR products were analyzed on a $1.5 \%$ agarose gel (SeaKem, FMC BioProducts, ME, USA) stained with $0.3 \mathrm{~g} / \mathrm{ml}$ ethidium bromide and were visualized under UV light.

Antimicrobial resistance testing: Campylobacter isolates were tested for resistance to different antimicrobials using the disc diffusion method on Muller Hinton Agar (Oxoid Ltd, Basingstoke, UK). Briefly, suspensions were prepared in a sterile normal saline and adjusted to a turbidity equivalent to $0.5 \mathrm{McF}$ arland standard. Inocula were spread onto Mueller-Hinton plates and dried; and then antibiotic discs were distributed over the inoculated plates using a BBL Sensi-disc dispenser (Oxoid Ltd, Basingstoke, UK). The plates were then incubated at $42^{\circ} \mathrm{C}$ for $48 \mathrm{~h}$ under microaerobic conditions. After $48 \mathrm{~h}$ diameters of inhibition zones were measured and the results interpreted based on both standardized tables supplied by the National Committee on Clinical Laboratory Standards (currently known as Clinical and Laboratory Standards Institute) [20] and manufacturer's instructions. Thirty 
Table-1: Antimicrobial resistance profiles of Campylobacter isolates derived from laboratory and farm animals (general)

\begin{tabular}{lccc}
\hline Antimicrobial agent tested & \multicolumn{3}{c}{ Proportion of resistant isolates (\%) } \\
\cline { 2 - 4 } & Overall $(\mathbf{n}=\mathbf{3 2})$ & Farm animal isolates $(\mathbf{n}=\mathbf{2 1})$ & Laboratory animal isolates $(\mathbf{n}=\mathbf{1 1})$ \\
\hline NA & 100.0 & 100.0 & 100.0 \\
CN & 9.4 & 14.3 & 0.00 \\
AMP & 12.5 & 14.3 & 9.1 \\
KF & 12.5 & 4.8 & 27.3 \\
AML & 12.5 & 19.0 & 0.00 \\
NOR & 62.5 & 52.3 & 81.8 \\
E & 50.0 & 52.4 & 45.5 \\
TE & 37.5 & 47.6 & 72.7 \\
CT & 87.5 & 95.2 & 36.4 \\
AZM & 37.5 & 38.1 & 9.0 \\
C & 25.0 & 33.3 & 18.2 \\
CIP & 6.25 & 0.00 & \\
\hline
\end{tabular}

$\mathrm{NA}=$ nalidixic acid, $\mathrm{CN}=$ gentamycin, $\mathrm{AMP}=$ ampicillin, $\mathrm{KF}=$ cephalothin, $\mathrm{AML}=$ amoxycillin, $\mathrm{NOR}=$ norfloxacin, $\mathrm{E}=$ erythromycin, $\mathrm{TE}=$ tetracycline, $\mathrm{CT}=$ colistin sulphate, $\mathrm{AZM}=$ azithromycin, $\mathrm{C}=$ chloramphenicol and $\mathrm{CIP}=$ ciprofloxacin

Table-2: Antimicrobial resistance profiles of Campylobacter isolates by species

\begin{tabular}{|c|c|c|}
\hline \multirow[t]{2}{*}{ Antimicrobial agent tested } & \multicolumn{2}{|c|}{ Proportion of resistant isolates (\%) } \\
\hline & C. jejuni $(\mathrm{n}=18)$ & C. coli $(n=14)$ \\
\hline NA & 100 & 100 \\
\hline $\mathrm{CN}$ & 0 & 21.42 \\
\hline AMP & 0 & 28.57 \\
\hline KF & 0 & 28.57 \\
\hline AML & 0 & 28.57 \\
\hline NOR & 27.8 & 100 \\
\hline $\mathrm{E}$ & 50.0 & 50.0 \\
\hline TE & 50.0 & 28.6 \\
\hline CT & 72.2 & 100 \\
\hline AZM & 50.0 & 28.6 \\
\hline C & 27.8 & 28.6 \\
\hline CIP & 5.6 & 7.1 \\
\hline
\end{tabular}

$\mathrm{NA}=$ nalidixic acid, $\mathrm{CN}=$ gentamycin, $\mathrm{AMP}=$ ampicillin, $\mathrm{KF}=$ cephalothin, $\mathrm{AML}=$ amoxycillin, $\mathrm{NOR}=$ norfloxacin, $\mathrm{E}=$ erythromycin, $\mathrm{TE}=$ tetracycline, $\mathrm{CT}=$ colistin sulphate, $\mathrm{AZM}=$ azithromycin, $\mathrm{C}=$ chloramphenicol and $\mathrm{CIP}=$ ciprofloxacin

two Campylobacter isolates were tested for resistance against the following antimicrobials; nalidixic acid $(30 \mu \mathrm{g})$, ciprofloxacin $(5 \mu \mathrm{g})$, gentamicin $(10 \mu \mathrm{g})$, ampicillin $(10 \mu \mathrm{g})$, cephalothin $(30 \mu \mathrm{g})$, amoxycillin $(25 \mu \mathrm{g})$, norfloxacin $(10 \mu \mathrm{g})$, erythromycin $(15 \mu \mathrm{g})$, tetracycline $(30 \mu \mathrm{g})$, colistin sulphate $(10 \mu \mathrm{g})$, azithromycin $(15 \mu \mathrm{g})$ and

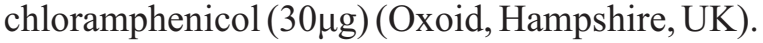

Statistical analysis: Data were entered in Microsoft excel and analyzed in MedCalc ${ }^{\mathrm{TM}}$. Descriptive statistics were computed to determine the prevalence of thermophilic Campylobacter infections in different animal species and the proportions of Campylobacter isolates resistant to different antibiotics.

\section{Results}

Occurrence of thermophilic Campylobacter in the sampled animals: Among the sampled laboratory animals $8(26.7 \%)$ guinea pigs and $3(1.2 \%)$ rats were colonized with Campylobacter. PCR results indicated that four isolates from the guinea pigs and two isolates from rats were $C$. jejuni and the rest were $C$. coli. In farm animals, thermophilic Campylobacter were detected from $18(31.6 \%)$ sheep and $3(60 \%)$ horses. Based on PCR, 12 isolates (10 from sheep and 2 from horses) were $C$. jejuni and the remaining were $C$. coli.

Antimicrobial resistance profiles of thermophilic Campylobacter isolates: Antimicrobial resistance profiles for the isolates are presented in a Table-1 (general) and Table-2 (species specific). The isolates showed high levels of resistance to erythromycin, norfloxacin, colistin sulphate and nalidixic acid in ascending order; whereas low levels of resistance were observed for ciprofloxacin and gentamicin. As compared to $C$. jejuni, $C$. coli isolates had significantly higher resistance to norfloxacin. Furthermore, all the resistant isolates to gentamicin, amoxicillin, ampicillin and cephalothin were $C$. coli.

\section{Discussion}

Our findings indicate an occurrence of thermophilic Campylobacter in horses and sheep among the sampled farm animals. The isolation of Campylobacter spp in these hosts may be attributed to contamination from pigs and chickens. Sheep's dwelling unit is in close proximity to chickens'; whereas horses' dwelling units are occasionally used to host pigs. Poultry and pigs are known to be the most leading animal species in harboring Campylobacter organisms [21]. A study by Jiwa et al. [22] detected $C$. coli in goats that were kept close to C. coli positive pigs and chickens; while goats kept away from these other farm animals, irrespective of whether the management system was good or poor, were negative for Campylobacter spp. Detection of the organisms in horses [23-24] and in sheep [23, 25-34] has also been reported in previous investigations. This 
further indicates a multihost nature of the organism which provides for many sources of human infections. Studies in USA [35] and Norway [25] were not able to isolate thermophilic Campylobacter from horses.

Previous investigations in camels, cattle [36] and goats $[23,25,37]$ found these animals to be free from colonization with thermophilic Campylobacter. The findings of these studies are consistent with the results of our study. Some other studies however detected thermophilic Campylobacter in these animal species. Occurrence of these organisms in camels was reported in South Iran [24] and in Nigeria [38]; whereas occurrence of the organisms in cattle and goats was reported at variable rates both in this country [22, 39, 40] and elsewhere [24, 26-28, 30, 31, 33, 41-46]. Some authors attributed occurrence of the organism in goats to bad management practices $[22,37]$. This and other possible reasons could imply differences in exposure rates of these animal species to potential sources of infections [37].

Among laboratory animals, guinea pigs (26.7\%) and rats $(1.2 \%)$ were found to be colonized with thermophilic Campylobacter. The level of infection in guinea pigs was higher than that reported earlier in New Zealand [47]. The level of infection in rats on the other hand was lower than those obtained previously $[47,48]$. In a study conducted in England involving guinea pigs [48], no thermophilic Campylobacter could be isolated. Similar to findings in this study some other studies on thermophilic Campylobacter infections in laboratory animals involving rabbits [35, 48] and mice [48] were not able to isolate the organisms from sampled individuals. Colonization of rabbits [47] and mice [40, 49] with thermophilic Campylobacter has however been reported in Tanzania and New Zealand. Some authors have considered mice and rats to be likely sources of introduction of Campylobacter into chicken and pig rearing units $[49,50]$.

Our results indicate that the differences in isolation frequencies between $C$. jejuni and $C$. coli in both laboratory and farm animals were not statistically significant. This observation differs with many other studies both in animals and humans in which $C$. jejuni prevails [30-51]. In many studies involving pigs however C. coli is the commonly isolated Campylobacter spp. [52-55]. The differences in species isolations may depend on common Campylobacter spp. circulating in the local environment.

There are reports from different parts of the world that antimicrobial resistance is increasing in food, food animals and in human bacterial isolates [51, 56-59]. This is also evident in the present study in which varied proportions of thermophilic Campylobacter were resistant to different antimicrobials. The isolates demonstrated high levels of resistance to erythromycin (50\%), norfloxacin $(62.5 \%)$, colistin sulphate $(87.5 \%)$ and nalidixic acid (100\%); whereas low levels of resistance was observed for ciprofloxacin and gentamicin. Occurrence of resistant isolates to these antimicrobials is of public health concern as antibiotic resistant Campylo- bacter species from animals can infect humans via occupational exposure or through the food chain [6063]. Thus, variations in resistance observed over time underscore the need for continued public health monitoring of Campylobacter resistance from humans, animals, and food [64].

Though most cases of human campylobacteriosis are self-limiting, therapeutic intervention is indicated in persistent or complicated cases and those involving immuno-compromised individuals [65]. Fluoroquinolone (ciprofloxacin) and macrolides (erythromycin) are the drugs of choice for the treatment of human campylobacteriosis. Studies in Nigeria [66-67] reported that ciprofloxacin was effective against all the strains of Campylobacter tested. Varying proportions of resistant Campylobacter isolates to ciprofloxacin and erythromycin have however been reported in different studies [51, 54, 55, 68-70]. In the current study $6.25 \%$ and $50 \%$ of thermophilic Campylobacter isolates were resistant to ciprofloxacin and erythromycin, respectively. The low level of resistance observed for ciprofloxacin indicates that this antibiotic is still useful in the treatment of human campylobacteriosis. High level of resistance to erythromycin on the other hand indicates that this drug would be of little use for the treatment of campylobacteriosis. Beatty et al. [71] reported that the resistance of Campylobacter to erythromycin is increasing and varies between $12 \%$ and $95 \%$.

The frequency of tetracycline resistant thermophilic Campylobacter isolates in this study was $37.5 \%$. Another study conducted in the country [10] recorded resistance level of $74 \%$ to tetracyclines among $C$.jejuni isolates derived from ducks. Tetracyclines are the most extensively used drugs in veterinary medicine in Tanzania. In Canada, Gaudreau and Gilbert [72] reported that the rate of resistance of $C$. jejuni to tetracycline rose from $19.1 \%$ to $55.7 \%$ in a period of 10 years. Tetracyclines are known to be relatively cheap and have a broad spectrum of activity. For this reason, they have been broadly used in the prophylaxis and therapy of human and animal infections and to promote animal growth.

Investigations elsewhere reported that $C$. coli isolates are more resistant to antimicrobials than $C$. jejuni strains $[54,73,74]$. In the present study $C$. coli isolates were frequently resistant to norfloxacin as compared to $C$.jejuni. It was also noted that only $C$. coli isolates showed resistance to gentamicin, ampicillin, cephalothin and amoxicillin. Some other studies have reported higher resistance to ciprofloxacin, a drug of choice for treatment of human campylobacteriosis, among $C$. coli isolates compared to $C$. jejuni [75-76]. In a study by de Jong et al. [74] C. coli isolates were seen to display higher resistance to erythromycin when compared to C.jejuni.

\section{Conclusion}

In conclusion, Campylobacter organisms colonize 
a diverse range of animal hosts including farm and laboratory animals resulting in asymptomatic carriers. This has a substantial impact on public health with regard to sources of human infections. The occurrence of antimicrobial resistant Campylobacter strains from the study animals further complicates the situation. Therefore, we recommend consideration of all those reservoirs of the organisms when planning to stem human infections and the problem of antimicrobial resistance.

\section{Authors' contributions}

EVGK, RHM and PLMM designed the experiment. Sample collection and experiments were performed by DEM and MJM under supervision of EVGK. Manuscript preparation was done by EVGK. RHM and PLMM reviewed and edited the manuscript. All authors read and approved the final manuscript.

\section{Acknowledgements}

The authors are grateful to the Government of the United Republic of Tanzania for financing this study through Higher Education Students Loans Board (HESLB).

\section{Competing interests}

The authors declare that they have no competing interests.

\section{References}

1. Skirrow, M.B. and Butzler, J.P. (2000) Foreward. In: Nachamkin, I. and Blaser, M.J., editors. Campylobacter. $2^{\text {nd }}$ edition. Washington DC: American Society for Microbiology Press. p17-23.

2. Oberhelman, R.A. and Taylor, D.N. (2000) Campylobacter infections in developing countries. In: Nachamkin, I. and Blaser, M.J., editors. Campylobacter. $2^{\text {nd }}$ edition. Washington DC: American Society for Microbiology Press. p139-153.

3. Heuer, O.E., Pedersen, K., Andersen J.S. and Madsen, M. (2001) Prevalence and antimicrobial susceptibility of thermophilic Campylobacter in organic and conventional broiler flocks. Danish Veterinary Laboratory Copenhagen. Denmark. Lett. Appl. Microbiol. 33: 269-274.

4. Rzewuska, K., Korsak, D. and Maćkiw, E. (2010) Antibiotic resistance of bacteria Campylobacter spp. Przeglad Epidemiologiczny. 64(1): 63-68.

5. Wilson, D.J, Gabriel E., Leatherbarrow, A.J.H., Cheesbrough, J., Gee, S., Bolton, E., Fox, A., Fearnhead, P., Anthony Hart, C. and Diggle, P.J. (2008) Tracing the Source of Campylobacteriosis. PLoS Genet. 4(9): e1000203.

6. Meinersmann, R.J., Rigsby, W.E., Stern, N.J., Kelley, L.C., Hill, J.E., Doyle, M.P. (1991) Comparative study of colonizing and non colonizing Campylobacter jejuni. Am J Vet Res. 52: 1518-1522.

7. Babakhani, F.K., Bradley, G.A. and Joens L. A. (1993) Newborn piglet model for Campylobacteriosis. Infect. Immun. 61:3466-3475.

8. Ketley, J.M. (1997) Pathogenesis of Enteric infection by Campylobacter. Microbiology. 143: 5-21.

9. Mdegela, R.H., Nonga, H.E., Ngowi, H.A. and Kazwala, R.R. (2006) Prevalence of Thermophilic Campylobacter Infections in Humans, Chickens and Crows in Morogoro, Tanzania. JVet Med B. 53:116-121.

10. Nonga, H.E. and Muhairwa A.P. (2009) Prevalence and antibiotic susceptibility of thermophilic Campylobacter isolates from free range domestic duck (Cairina moschata) in Morogoro municipality, Tanzania. Trop Anim Health
Prod. 42 (2): 165-172.

11. Kaur, T., Singh, J., Huffman, M.A., Petrželkova, K.J., Taylor. N. S., Xu, S., Dewhirst, F.E., Paster, B.J., Debruyne, L., Vandamme, P. and Fox, J.G. (2011) Campylobacter troglodytis sp. nov., Isolated from Feces of HumanHabituated Wild Chimpanzees (Pan troglodytes schweinfurthii) in Tanzania. Appl. Environ. Microbiol. 77 (7): 2366-2373.

12. Takamiya, M., Ozen, A., Rasmussen, M., Alter, T., Gilbert, T., Ussery D.W. and Knøchel, S. (2011) Genome Sequence of Campylobacter jejuni strain 327, a strain isolated from a turkey slaughterhouse. Stand Genomic Sci. 4: 113-122.

13. Man, S.M. (2011) The clinical importance of emerging campylobacter species. Nat Rev Gastroenterol Hepatol. 8: 669-685.

14. Berrang, M.E., Buhr, R.J., Cason, J.A. and Dickens, J.A. (2001) Broiler carcass contamination with Campylobacter from Feces during Defeathering. J Food Prot. 64: 20632066.

15. Lindmark H, Boqvist, S., Ljungstrom, M., Björkholm, B., Agren, P. and Engstrand, L. (2009) Risk Factors for Campylobacteriosis: an Epidemiological Surveillance Study of Patients and Retail Poultry. J clin microbiol. 47(8): 26162619.

16. Skirrow, M.B. and Blaser M.J. (2000) Clinical Aspects of Campylobacter Infection. In: Nachamkin, I. and Blaser, M.J., editors. Campylobacter. $2^{\text {nd }}$ edition. Washington DC: American Society for Microbiology Press. p69-88.

17. Nachamkin, I., Allos, B.M. and Ho, T. (1998) Campylobacter species and Guillain-Barre syndrome. Clin Microbiol Rev. 11: 555-567.

18. Aarestrup, F.M. and Engberg, J. (2001) Antimicrobial resistance of thermophilic Campylobacter. Vet Res. 32(3-4): 311-21.

19. Jacob, P., Mdegela, R.H. and Nonga, H.E. (2011) Comparison of Cape Town and Skirrow's Campylobacter isolation protocols in humans and broilers in Morogoro, Tanzania. Trop Anim Health Prod. 43(5): 1007-1013.

20. NCCLS, (2002) Perfomance standards for antimicrobial disk diffusion and dilution susceptibility tests for bacteria isolated from animals. National Committee for Clinical Laboratory Standards (NCCLS), Pennsylvania.

21. Turkson, P.K., Lindqvist, K.J. and Kapperud, G. (1988) Isolation of Campylobacter spp and Yersinia enterocolitica from domestic animals and humans patients in Kenya. APMIS. 96: 141-146.

22. Jiwa, S.F.H., Kazwala, R.R. and Namahungu, E. (1994a) Prevalence of Campylobacter spp. in clinically normal goats kept under various management systems in urban Tanzania. Small Ruminant Res. 15:97-100

23. Manser, P.A. and Dalziel, R.W. (1985) A survey of campylobacter in animals. Jhyg. 95: 15-21.

24. Baserisalehi, M., Bahador, N. and Kapadnis, B.P. (2007) Isolation and characterization of Campylobacter spp. from domestic animals and poultry in south of Iran. PakJ Biol Sci. 10(9): 1519-1524.

25. Rosef, O., Gondrosen, B., Kapperud, G. and Underdal, B. (1983) Isolation and characterization of Campylobacter jejuni and Campylobacter coli from domestic and wild mammals in Norway. Appl. Environ. Microbiol. 46: 855-859.

26. Abrahams, C.A., Agbodaze, D., Nakano, T., Afari, E.A. and Longmatey, H.E. (1990) Prevalence and antibiogram of Campylobacter jejuni in domestic animals in rural Ghana. Arch Environ Health. 45(1): 59-62.

27. Khalil, K., Lindblom, G.B., Mazhar, K., Sjögren, E. and Kaijser, B. (1993) Frequency and enterotoxigenicity of Campylobacter jejuni and C. coli in domestic animals in Pakistan as compared to Sweden. J Trop Med Hyg. 96(1): 35-40.

28. Adesiyun, A.A., Kaminjolo, J.S., Loregnard, R. and KitsonPiggott, W. (1992) Campylobacter infections in calves, piglets, lambs and kids in Trinidad. Brit Vet J. 148(6): 547556. 
29. Stanley, K.N., Wallace, J.S., Currie, J.E., Diggle, P.J. and Jones, K. (1998) Seasonal variation of thermophilic campylobacters in lambs at slaughter. $J$ Appl Microbiol. 84: 1111-1116.

30. Kassa, T., Gebre-Selassie, S. and Asrat, D. (2005) Prevalence of thermophilic Campylobacter Spp,in food animals in Jimma zone, Southwest Ethiopia. Ethiop J Health Dev. 42: 83-90.

31. Oporto, B., Esteban, J.I., Aduriz, G., Juste, R.A. and Hurtado, A. (2007) Prevalence and strain diversity of thermophilic campylobacters in cattle, sheep and swine farms. JAppl. Microbiol. 103:977-984.

32. Açik, M.N. and Cetinkaya, B. (2006) Heterogeneity of Campylobacter jejuni and Campylobacter coli strains from healthy sheep. Vet Microbiol. 115(4): 370-375.

33. Milnes, A.S., Stewart, I., Clifton-Hadley, F.A., Davies, R.H., Newell, D.G., Sayers, A.R., Cheasty, T., Cassar, C., Ridley, A., Cook, A.J., Evans, S.J., Teale, C.J., Smith, R.P., McNally, A., Toszeghy, M., Futter, R., Kay, A., Paiba, G.A. (2008) Intestinal carriage of verocytotoxigenic Escherichia coli O157, Salmonella, thermophilic Campylobacter and Yersinia enterocolitica, in cattle, sheep and pigs at slaughter in Great Britain during 2003. Epidemiol Infect. 136(6): 739751.

34. Woldermariam, T., Asrat, D. and Zewde, G. (2009) Prevalence of Thermophilic Campylobacter Species in Carcasses from Sheep and Goats in Ethiopia. Ethiop J Health Dev. 23 (3): 229-233.

35. Roug, A., Byrne, B.A., Conrad, P.A. and Miller, W.A. (2013) Zoonotic fecal pathogens and antimicrobial resistance in county fair animals. Comp Immunol Microbiol Infect Dis. 36(3): 303-308.

36. Pantozzi, F.L., Moredo, F.A., Vigo, G.B. and Giacoboni G.I. (2010) Antimicrobial resistance in indicator and zoonotic bacteria isolated from domestic animals in Argentina. Rev Argent Microbiol. 42: 49-52.

37. Cortés, C., de la Fuente, R., Contreras, A., Sánchez, A., Corrales, J.C., Martínez, S. and Orden, J.A. (2006) A survey of Salmonella spp and Campylobacter spp in dairy goat faeces and bulk tank milk in the Murcia region of Spain. Ir Vet J. 59 (7): 391-393.

38. Salihu, M.D., Junaidu, A.U., Abubakar, M.B., Magaji, A.A. and Mohammed, L.G. (2009) Isolation and characterization of thermophilic campylobacter species from Camels (Camelus dramedarius) in Sokoto state, Northwestern Nigeria. Int JAnim Veter Adv. 1(1), 25-27.

39. Kusiluka, L.J.M., Karimuribo, E.D., Mdegela, R.H., Luoga, E.J., Munishi, P.K.T., Mlozi M.R.S. and Kambarage, D.M. (2005) Prevalence and impact of water-borne zoonotic pathogens in water, cattle and humans in selected villages in Dodoma Rural and Bagamoyo districts, Tanzania. Phys Chem Earth. 30 (11-16): 818-825.

40. Jiwa, S.F.H., Phiri, E.C.J.H. and Kimera, S.I. (1994b) Isolation of thermophilic Campylobacter from clinically normal calves, goats, field mice and purging children at Sokoine University of Agriculture (SUA) campus, Morogoro, Tanzania. Tanz vet J. 14(3-4): 103-109.

41. Raghunath, V. and Banker, D.D. (1993) Isolation of Campylobacter from human and other sources in Bombay. Indian J Pathol Microbiol. 36(3): 211-214.

42. Lee, M.K., Billington, S.J. and Joens, L.A. (2004) Potential virulence and antimicrobial susceptibility of Campylobacter jejuni isolates from food and companion animals. Foodborne Pathogen Dis. 1(4): 223-230.

43. Bae, W., Kaya, K.N., Hancock, D.D., Call, D.R., Park, Y.H. and Besser, T.E. (2005) Prevalence and antimicrobial resistance of thermophilic Campylobacter spp. from cattle farms in Washington State. Appl Environ Microbiol. 71(1): 169-174.

44. Hakkinen, M., Heiska, H, and Marja-Liisa, H. (2007) Prevalence of Campylobacter species in Cattle in Finland and Antimicrobial Susceptibilities of Bovine Campylobacter jejuni Strains. Appl Environ Microbiol. 73: 3232-3238.

45. Ellis-Iversen, J., Pritchard, G.C., Wooldridge, M. and Nielen, M. (2009) Risk factors for Campylobacter jejuni and Campylobacter coli in young cattle on English and Welsh farms. Prev Vet Med. 88(1): 42-48.

46. Châtre, P., Haenni, M., Meunier, D., Botrel, M.A., Calavas, D. and Madec, J.Y. (2010) Prevalence and antimicrobial resistance of Campylobacter jejuni and Campylobacter coli isolated from cattle between 2002 and 2006 in France. $J$ Food Prot. 73(5): 825-31.

47. Meanger, J.D. and Marshall R.B. (1989b) Campylobacter jejuni infection within a laboratory animal production unit. Lab animal. 23(2): 126-132.

48. Fernie, D.S. and Park R.W.A. (1977) The isolation and nature of campylobacters (microaerophilic vibrios) from laboratory and wild rodents. JMed Microbiol. 10: 325-329.

49. Kapperud, G., Skjerve, E., Vik, L., Hauge, K., Lysaker, A. and Aalmen, I. (1993) Epidemiological investigation of risk factors for Campylobacter colonization in Norwegian flocks. Epidemiol Infect. 111:245-255.

50. Annan-Prah, A. and Jane, M. (1988) The mode of spread of Campylobacter jejuni/coli to broiler flocks. Zentralbl Veterinarmed B. 35: 11-18.

51. González-Abad, M.J. and Alonso-Sanz, M. (2013) Incidence and susceptibility of Campylobacter jejuni in pediatric patients: involvement in bacteremia. Rev Esp Quimioter. 6(2): 92-96.

52. Jensen, A.N., Dalsgaard, A., Baggesen, D.L. and Nielsen, E.M. (2006) The occurrence and characterization of Campylobacter jejuni and C. coli in organic pigs and their outdoor environment. Vet Microbiol. 116(1-3): 96-105.

53. Wright, S.L., Carver, D.K., Siletzky, R.M., Romine, S., Morrow, W.E. and Kathariou, S. (2008) Longitudinal study of prevalence of Campylobacter jejuni and Campylobacter coli from turkeys and swine grown in close proximity. JFood Prot. 71(9): 1791-6.

54. Tambur, Z., Miljkovic-Selimovic, B., Bokonjic, D. and Kulisic, Z. (2009) Susceptibility of Campylobacter jejuni and Campylobacter coli isolated from animals and humans to ciprofloxacin. PolJ Vet Sci. 12(2): 269-73.

55. Wieczorek, K. and Osek, J. (2013) Characteristics and antimicrobial resistance of Campylobacter isolated from pig and cattle carcasses in Poland. PolJ Vet Sci. 16(3): 501-508.

56. Thorsteinsdottir, T.R., Kristinsson, K.G., Fridriksdottir, V. and Gunnarsson, E. (2008) Antimicrobial Resistance of Campylobacter Spp. Isolated from Broiler Flocks. Microb drug resist. 14(1): 49-53.

57. Guevremont, E., Nadeau, E. and Sirois, M. (2006) Antimicrobial susceptibilities of thermophilic Campylobacter from humans, swine, and chicken broilers. Can JVet Res. 70: 81-86.

58. Praakle-Amin, K., Roasto, M., Korkeala, H. and Hänninen, M.L. (2007) PFGE genotyping and antimicrobial susceptibility of Campylobacter in retail poultry meat in Estonia. Int J Food Microbiol. 114: 105-112.

59. Dadi, L. and Daniel, A., 2008 Prevalence and antimicrobial susceptibility profiles of thermotolerant Campylobacter strains in retail raw meat products in Ethiopia, Ethiop $J$ Health Dev. 22(2): 195-200.

60. Van de Bogaard, A.E. and Stobberingh, E.E. (2000) Epidemiology of resistance to antibiotics links between animals and humans. Int J Antimicrob Ag. 14: 327-335.

61. Nachamkin, I., Ung, H. and Li, M. (2001) Fluoroquinolone resistant Campylobacter jejuni in Philadelphia, 1982-2000. [Abstract B-06]. In: Hacker J, editor. Abstracts of scientific presentations of the 11th International Workshop on Campylobacter, Helicobacter and Related Organisms, Freiburg, Germany, Sept 1-5, 2001. Int J Med Microbiol. 291(31): 6 .

62. Fallon, R., O'Sullivan, N., Maher, M. and Carrol, C. (2003) Antimicrobial resistance of Campylobacter jejuni and Campylobacter coli isolates from broiler chicken isolated at 
an Irish poultry processing plant. Lett Appl Microbiol. 36: 277-281.

63. Bae, W., Katherine, N.K., Dale, D.H., Douglas, R.C., Yong, H.P. and Thomas, E. B. (2004) Prevalence and antimicrobial resistance of thermophilic Campylobacter spp. from cattle farms in Washington State. Appl Environ Microbiol. 71: 169174.

64. Ge, B., Wang, F., Sjölund-Karlsson, M. and McDermott, P.F. (2013) Antimicrobial resistance in campylobacter: susceptibility testing methods and resistance trends. $J$ Microbiol Methods. 95(1): 57-67.

65. Wimalarathna, H.M.L., Richardson, J.F., Lawson, A.J., Elson, R., Meldrum, R., Little, C.L., Maiden, M.C.J., McCarthy, N.D. and Sheppard, S.K. (2013) Widespread acquisition of antimicrobial resistance among Campylobacter isolates from UK retail poultry and evidence for clonal expansion of resistant lineages. BMC Microbiol. 13: 160 .

66. Samuel, S.O., Aboderin, A.O., Akanbi II, A.A., Adegboro, B., Smith, S.I. and Coker, A.O., 2006. Campylobacter enteritis in Ilorin, Nigeria. East Afr Med J. 83: 478-484.

67. Kownnhar, H., Shankar, E.M., Rajan, R., Vengatesan, A. and Rao, U.A. (2007) Prevalence of Campylobacter jejuni and enteric bacterial pathogens among hospitalized HIV infected versus non-HIV infected patients with diarrhoea in southern India. Scand J Infect Dis. 39: 862-866.

68. Jacobs-Reitsma, W.F., Koenraad, P.M., Bolder N.M. and Mulder R.W. (1994) In vitro susceptibility of Campylobacter and Salmonella isolates from broilers to quinolones, ampicillin, tetracycline, and erythromycin. Vet $Q .16$ : 206208.

69. Deckert, A.E., Reid-Smith, R.J., Tamblyn, S.E., Morrell, L., Seliske, P., Jamieson, F.B., Irwin, R., Dewey, C.E., Boerlin, P. and McEwen, S.A. (2013) Antimicrobial resistance and Antimicrobial use associated with laboratory-confirmed cases of Campylobacter infection in two health units in Ontario. Can Jinfect Dis and Med Microbiol. 24(1): e16-21.
70. Carrique-Mas, J.J., Bryant, J.E., Cuong, N.V., Hoang, N.V., Campbell, J., Hoang, N.V., Dung, T.T., Duy, D.T., Hoa, N.T., Thompson, C., Hien, V.V., Phat, V.V., Farrar, J., Baker, S. (2013) An epidemiological investigation of Campylobacter in pig and poultry farms in the Mekong delta of Vietnam. Epidemiol Infect. 25: 1-12.

71. Beatty, M.E., Ochieng, J.B., Chege, W., Kumar, L., Okoth, G., Shapiro, R.L., Wells, J.G., Parsons, M.B., Bopp, C., Chiller, T., Vulule, J., Mintz, E., Slutsker, L. and Brooks, J.T. (2009) Sporadic paediatric diarrhoeal illness in urban and rural sites in Nyanza Province, Kenya. East Afr Med J. 86: 387-398.

72. Gaudreau, C. and Gilbert, H. (2003) Antimicrobial resistance of Campylobacter jejuni subsp. jejuni strains isolated from humans in 1998 to 2001 in Montréal, Canada. Antimicrob Agents Chemother. 47: 2027-2029.

73. Gallay, A., Prouzet-Mauleon, V., Kempf, I., Lehours, P., Labadi, L., Camou, C., Denis M, de Valk, H., Desenclos, J.C. and Megraud, F. (2007) Campylobacter antimicrobial drug resistance among humans, broiler chickens, and pigs, France. Emerg Infect Dis. 13(2): 259-266.

74. de Jong, A., Thomas, V., Simjee, S., Godinho, K., Schiessl, B., Klein, U., Butty, P., Vallé, M., Marion, H. and Shryock, T.R. (2012) Pan-European monitoring of susceptibility to human-use antimicrobial agents in enteric bacteria isolated from healthy food-producing animals. J Antimicrob Chemother. 67: 638-651.

75. Pezzotti, G., Serafin, A., Luzzi, I., Mioni, R. and Perin, R. (2003) Occurrence and resistance to antibiotics of Campylobacter jejuni and Campylobacter coli in animals and meat in northeastern Italy. Int J Food Microbiol. 82: 281287.

76. Taremi, M., Soltan, Dallal, M.M., Gachkar, L., MoezArdalan, S., Zolfaghari, K. and Zali, M.R. (2006) Prevalence and antimicrobial resistance of Campylobacter isolated from retail raw chicken and beef meat, Tehran, Iran. Int J Food Microbiol. 108: 401-403. 